\title{
Factorial Analysis on Sulfide Removal from Petrochemical Industry Wastewater using Acclimatized Activated Sludge
}

\author{
Norazwina Zainol, Akmal Arif B. Mohamed Zaki, Nur Hidayah Mat Yasin, Sunarti Abd Rahman, Azilah Aziz, Chin Sim \\ Yee \\ Faculty of Chemical Engineering and Natural Resources, University Malaysia Pahang, Lebuhraya Tun Razak, 26300 Kuantan, Pahang, \\ Malaysia
}

\begin{abstract}
In wastewater treatment, sulfide or hydrogen sulfide is a major problem in refining process and can cause the pollution in the wastewater plant. In this study, acclimatized activated sludge was used to remove sulfide from the petrochemical wastewater. Five independent factors which affecting the degradation of sulfide were investigated in this paper - wastewater/acclimatized activated sludge (WW/AS) ratio, type of system, temperature, agitation and hydraulic retention time (HRT). Fractional factorial design was used to investigate the effect of independent factors as well as the interaction factors on the sulfide and COD removals $(\%)$. Some of the independent factors were shown to have significant effect on sulfide removals (\%). The results obtained here showed that the order of significance in sulfide removal (\%) is as follows: agitation $>$ WW/AS ratio $>$ type of system $>$ temperature $>$ HRT. Amongst of the operation factors in question, it was found that the interaction factor of temperature*WW/AS ratio had the strongest effect on the sulfide removal (\%).
\end{abstract}

\section{Introduction}

Petroleum and petrochemical industry produced more than 2500 useful products from crude oil [1]. The petrochemical industry also includes the treatment of hydrocarbon such as sulfide from the petroleum refining industry and natural gas liquid in oil and gas industry [2]. Most sulfide in nature are produced biologically (under anaerobic conditions) and occurs as free hydrogen sulfide $\left(\mathrm{H}_{2} \mathrm{~S}\right)$. Even concentrations as low as $0.1 \mu \mathrm{g} / \mathrm{L}$, the odor of hydrogen sulfide can be detected and may be offensive in the plant area and the surrounding communities [3].

Therefore, wastewater treatment is important in petrochemical industry to remove the contaminated wastewater which usually enriched with high sulfide concentrations. Various methods to remove sulfide from petrochemical industry are available such as microbial fuel cells (MFCs), anaerobic method and chemical reaction by using hydrogen peroxide [4]. However, up to date any of the mentioned methods are still not yet commercially used because of high cost of maintenance. Thus, the activated sludge process was used in this research as a strategy to control the problem. Activated sludge is a process for treating sewage and industrial wastewaters using air and a biological floc composed of bacteria and protozoa in that wastewater to trap the sulfide [5]. This process uses a mass of microorganism (bacteria) to aerobically treat wastewater [6].

In this industrial research, factorial analysis was performed by using the concept of two level factorial (TLF) via Design Expert software. TLF is a statistical method based on the multivariate non-linear model that is useful in studying interactions of various parameters affecting the process [7-8]. Factorial analysis was applied to determine the most important factors that affecting sulfide removal from petrochemical industry wastewater. Based on the requirement from industry, five selected factors on sulfide removal had been chosen which are wastewater to acclimatized activated sludge ratio (WW/AS), type of system, temperature, agitation and hydraulic retention time (HRT).

\section{Materials and Methods}

\subsection{Synthetic Wastewater Preparation}

The synthetic wastewater was prepared according to the sulfide and COD contents in the real petrochemical industry wastewater (PW) sample with the design basis of sulfide and COD were $30 \mathrm{mg} / \mathrm{L}$ and $150 \mathrm{mg} / \mathrm{L}$, respectively. Sodium sulfide and glucose were added into the synthetic wastewater to achieve the design basis.

\subsection{Acclimatization of Activated Sludge (AS)}

This process was conducted for adaptation of the activated sludge to the sulfide content in PW. The acclimatization process was done in $10 \mathrm{~L}$ of batch reactor. Initially, $1 \mathrm{~L}$ of activated sludge was mixed with $528 \mathrm{~mL}$ synthetic wastewater. Later the same volume of synthetic wastewater was added into the reactor daily for three weeks.

\subsection{Experimental Design}

In this study, five factors e.g. WW/AS ratio, type of system, temperature, agitation and HRT were taken into account to investigate their effects on sulfide removal (\%) using a $2^{4}$ fractional factorial design. The design of experiment was performed by Design Expert software where all the factors were randomized. Table 1 shows the design factors and levels were coded as -1 (low level) and +1 (high level) where low and high level indicates the lowest and highest range of the factors. Shake flask method was applied to study the reaction between 
synthetic wastewater and acclimatized activated sludge. 16 runs of experiments were conducted. The response of the experimental design was analyzed using ANOVA based on the p-value with $95 \%$ of confidence level. Later, experimental data was analyzed using Design Expert software to determine the most contributing factor and interaction between the factors.

Table 1. List of selected factors and level

\begin{tabular}{|c|c|c|}
\hline \multirow{2}{*}{ Factor } & \multicolumn{2}{|c|}{ Level } \\
\cline { 2 - 3 } & -1 & +1 \\
\hline WW/AS ratio & $1: 1$ & $3: 1$ \\
\hline Type of system & Closed & Open \\
\hline Temperature & 30 & 37 \\
\hline Agitation (RPM) & 0 & 100 \\
\hline HRT (hour) & 17 & 32 \\
\hline
\end{tabular}

\section{Results and Discussions}

\subsection{Screening of Factors Affecting on the Sulfide Removal (\%)}

The identification of the factors that to be effective on the sulfide removal was carried out through $2^{4}$ fractional design to determine the degree of the effect from the factors on the response. Independent factors such as WW/AS ratio, type of system, temperature, agitation and HRT have been taken into account to investigate their effect on sulfide removals (\%) and the range of response was from 98.26 to $99.83 \%$.

\subsection{Main Effect and Interaction Effect between Factors on the Sulfide Removal (\%)}

ANOVA analysis of sulfide removal (\%) using AS showed that $\mathrm{p}$-values of agitation (C) and WW/AS ratio (E) were smaller than 0.05 , which implies the significance of the independent factors. It is necessary to examine any interactions that are important in the experimental design analysis; the 2-way interactions show their significance at $95 \%$ confidence level. The regression equation (Equation (1)) represent the best description after the elimination of non-significant parameters $(p>0.01)$ from the experimental results. The final empirical models in terms of actual parameters were determined as follows:

Sulfide Removal $=+99.21-3.125 \mathrm{E}-3 * \mathrm{~A}-0.014 * \mathrm{~B}-$ $0.12 * \mathrm{C}+0.062 * \mathrm{D}-0.076 * \mathrm{E}-0.21 * \mathrm{~A} * \mathrm{~B}+0.29 * \mathrm{~B} * \mathrm{E}+$ $0.18 * \mathrm{~A} * \mathrm{E}-0.18 * \mathrm{~B} * \mathrm{C}$

where $\mathrm{A}$ is HRT, B is temperature, $\mathrm{C}$ is agitation, D is type of system and $\mathrm{E}$ is WW/AS ratio.

The Pareto Chart in Figure 1 showed the main effects and interaction effects of the factors for the sulfide removal. For main effect, it showed that agitation (factor C) gave the highest contribution for sulfide removal and followed by WW/AS ratio (factor E). For interaction effects, it showed that there were four interaction effects that contributed in removal of sulfide. There were two positive effects, interaction of temperature and WW/AS ratio (BE) and interaction of HRT and WW/AS ratio (AE). Positive effects mean that value of sulfide removal increased as the value of factors increased and vice versa for negative effects. The interaction of HRT and temperature $(\mathrm{AB})$ and interaction of temperature and agitation (BC) showed negative effects to sulfide removal.

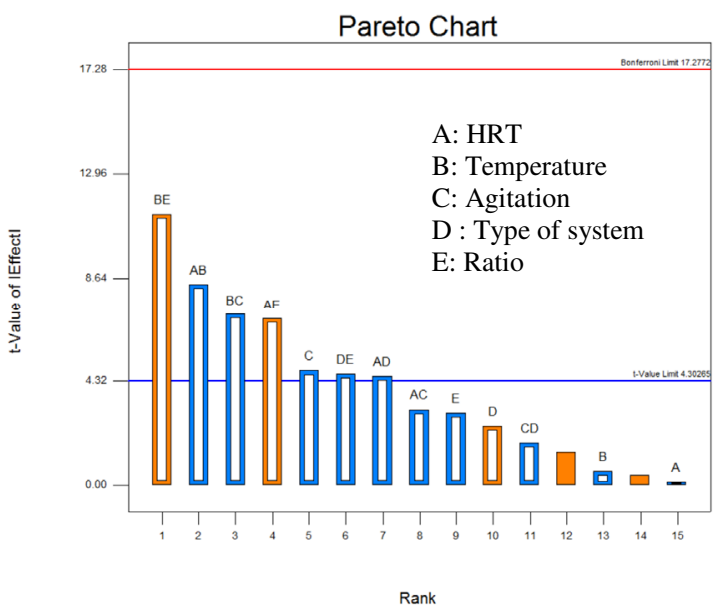

Figure 1. Contribution of independent and interaction effect to sulfide removal $(\%)$

\subsubsection{Effect of Independent Processing Parameters on Sulfide Removal (\%)}

The effects of two independent variables on the sulfide removal are shown in Figure $2 \mathrm{a}$ and Figure $2 \mathrm{~b}$. Sulfide removal decreased with increasing of agitation rate as shown Figure 2a. From the figure, sulfide removal was lower at $100 \mathrm{rpm}$ than at $0 \mathrm{rpm}$. However, there was no significant difference of sulfide removal between $0 \mathrm{rpm}$ and $100 \mathrm{rpm}$ of agitation where the sulfide removal achieved $99.3 \%$ and $99 \%$ at $0 \mathrm{rpm}$ and $100 \mathrm{rpm}$, respectively. The difference of sulfide removal at both agitation rate maybe due to the sensitivity of the microbes to the agitation where the agitation reduced the performance of the microbes in AS and reduced the sulfide removal [9]. Figure $2 \mathrm{~b}$ showed that sulfide removal was increased proportionally to WW/AS ratio where sulfide removal achieved $99.4 \%$ at $3: 1$ ratio and $99.2 \%$ at $1: 1$ ratio. Thus, it can be also concluded that there was still no significant difference of sulfide removal at both WW/AS ratios. This result is maybe affected by the application of AS for sulfide removal in this study. The acclimatized microbes in the wastewater can enhance degradation of organic pollutant compounds effectively [10]. 

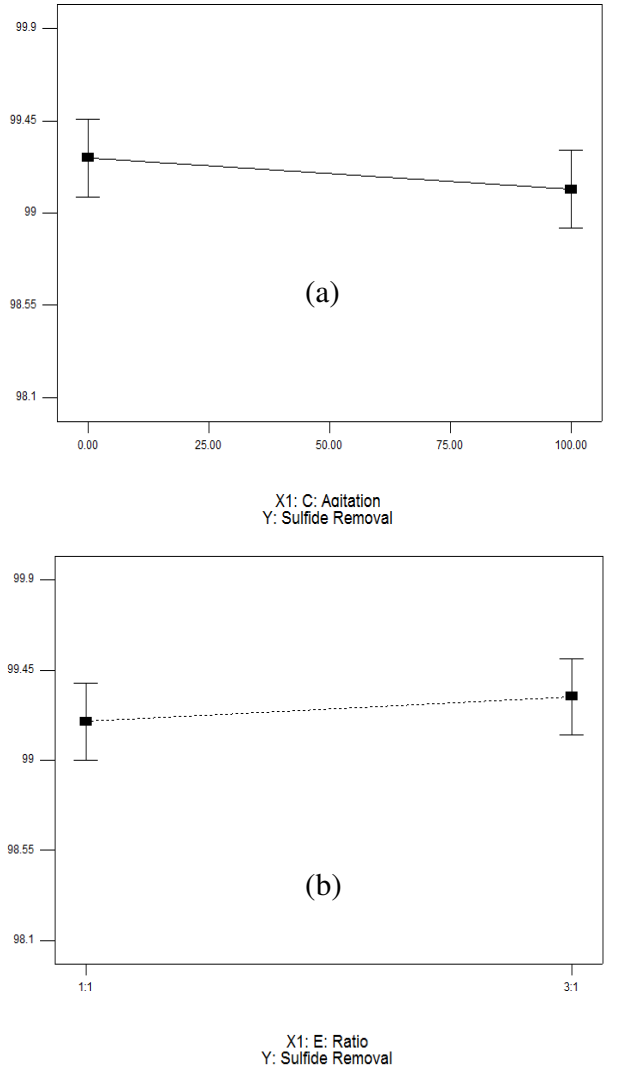

Figure 2. Most effective independent parameters in sulfide removal $(\%)$

\subsubsection{Interaction effects between factors on sulfide removal (\%)}

Figure 3a showed the interaction effect between temperature and WW/AS ratios on sulfide removal at specific conditions which were at HRT of 32 hours, no agitation and at open system. From Figure $3 \mathrm{a}$, it was observed that higher sulfide removal was achieved for $3: 1$ ratio than $1: 1$ ratio at higher temperature $\left(37^{\circ} \mathrm{C}\right)$. At lower temperature $\left(30^{\circ} \mathrm{C}\right)$, sulfide removal for $1: 1$ ratio was higher than 3:1 ratio. According to Siddique et al. [11], biological degradation is temperature dependent. At low temperature, it required more microbes to do the work while less microbes required at high temperature. Figure $3 \mathrm{~b}$ showed the interaction effect between temperatures and HRT on sulfide removal. The best condition for other factors was set at: no agitation, open system and 3:1 for WW/AS ratio. The figure was also showed that the sulfide removal was observed to be increased with the HRT for both temperatures but it was higher at temperature $37^{\circ} \mathrm{C}$ than $30^{\circ} \mathrm{C}$. According to Grady et al. [12], the maximum acceptable operating temperature for typical activated sludge is between $35^{\circ} \mathrm{C}$ to $40^{\circ} \mathrm{C}$, which correspond to the mesophilic organisms. This range of temperature was the best for the microbes to remove wastewater constituents such as sulfide. Figure $3 \mathrm{c}$ showed the interaction effect between temperature and agitation on sulfide removal. The result shows the increasing of sulfide removal as the temperature increased when no agitation applied. At 100 rpm of agitation sulfide removal decreased when the temperature increased. The sulfide removal decreased with agitation because the microbes were sensitive to the presence of agitation and reduced the performance of the microbes in the wastewater [9]. Figure $3 d$ showed the interaction effect between HRT and different WW/AS ratios on sulfide removal. From the result obtained in Figure 3d, sulfide removal increased proportionally with HRT values at 3:1 ratio and decreased when the HRT increased for 1:1 ratio. This observation is due to the low wastewater to AS volume ratio at $1: 1$ value where the wastewater represented as the food to the microbes. Thus, when the HRT increased, the food was limited to the microbes and will affect the sulfide removal process [11].
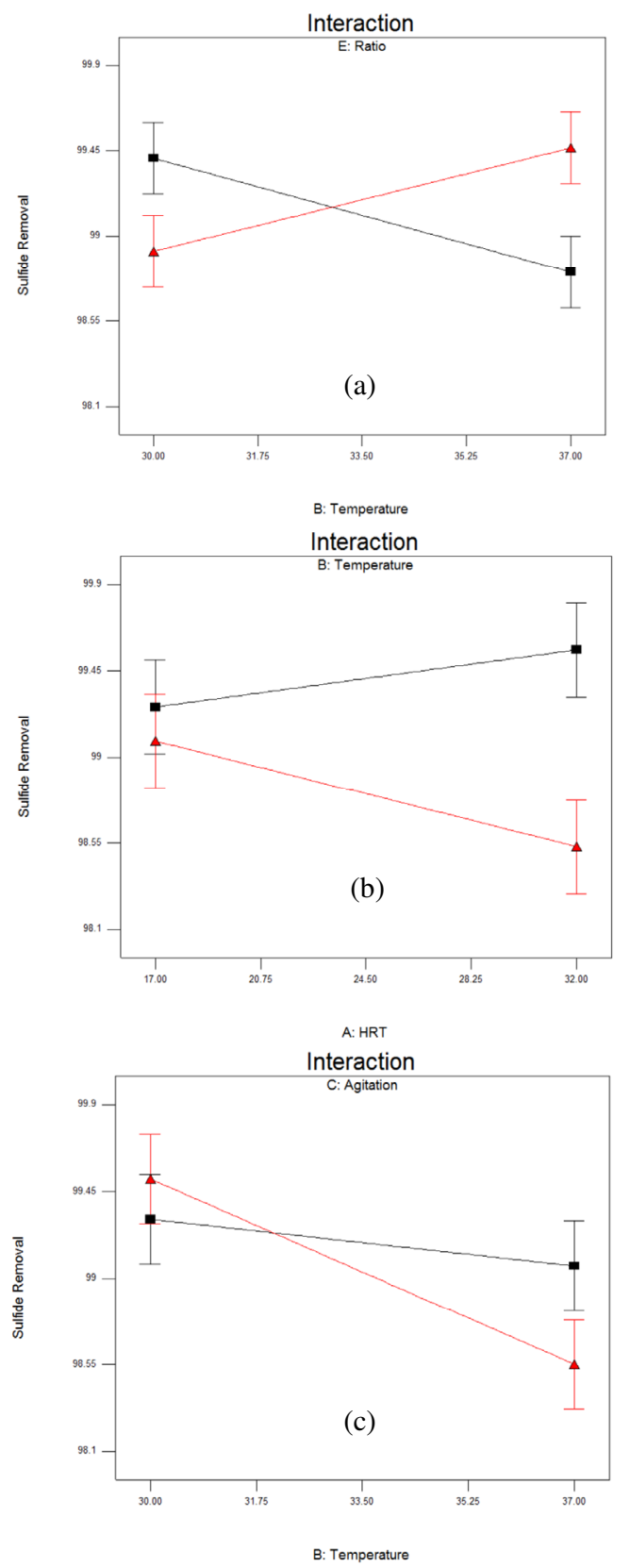


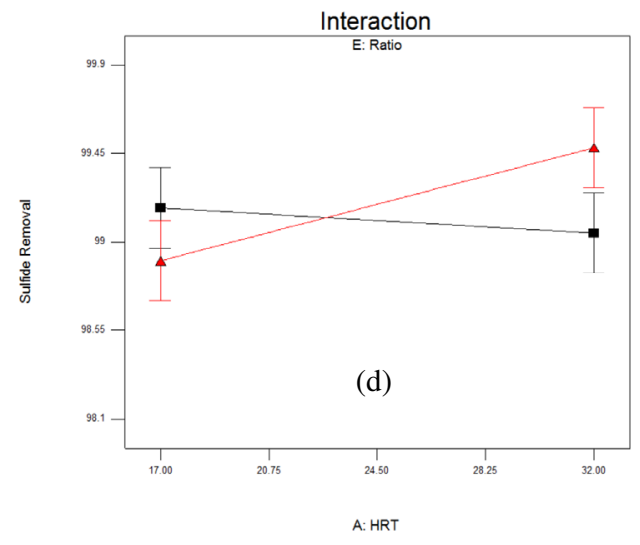

Figure 3. Interaction effect between factors on sulfide removal $(\%)$

\section{Conclusion}

The sulfide removal was studied using $2^{4}$ fractional factorial design. The effect of five factors e.g. WW/AS ratio, type of system, temperature agitation and HRT which affecting the sulfide removal was investigated. The determination of significance effect was based on $\mathrm{p}$ value $<0.05$, among all independent factors studied only agitation has significant effect on the removals. The sequence of the contributing factors with respect to decreasing of $\%$ contribution to sulfide removal was found to be: agitation $>$ WW/AS ratio $>$ type of system $>$ temperature $>$ HRT. Amongst the operation factors in question, interaction factor of temperature*WW/AS ratio had the strongest effect on the sulfide removal (\%). The results show that fractional factorial design is suitable in investigating the effect of large number of factors with a minimum number of experiments.

The authors would like to acknowledge the UMP Research Grant (Grant No. RDU 150396) from Universiti Malaysia Pahang, which has fully supported this research.

\section{References}

1. Bhaskar, N, Georgi S.C. (2009). Pollution Control Technologies - Volume III. EOLSS Publications, 30 Sep 2009.

2. Amosa, M. K., Mohammed, I.A. and Yaro, S.A. (2010). Sulphide Scavengers in Oil and Gas Industry - A Review. NAFTA 61 (2) 85-92

3. Gikunju, P., Njogu, P.M, Makhonge, P.X. (2016). Hydrogen sulphide concentrations a health risk to workers in geothermal power stations (A case study of Olkaria Geothermal Power Station in Kenya). Prime Journal of Engineering and Technology Research (PJETR), Vol. 2(1), pp. 38-51.

4. Izadi, P., Rahimnejad, M. (2014). Simultaneous electricity generation and sulfide removal via a dual chamber microbial fuel cell. Biofuel Research Journal, 1: 34-38
5. Dohare, D., Meshram, R. (2014). Biological Treatment of Edible Oil Refinery Wastewater using Activated Sludge Process and Sequencing Batch Reactors - A Review. International Journal of Engineering Sciences \& Research Technology, 251260, 2014

6. Mkhize, S. P., Atkinson, B. W., Bux, F. (2000). Assessment of A Biological Nutrient Removal Process For Remediation Of Edible Oil Effluent, Presented at WISA 2000

7. Bergquist, B. (2015). Analysis of an replicated $2^{2}$ factorial experiment performed in a continuous process.Total Quality Management, Vol 26, No 10: 1083-1094

8. Saunders, I. W., Hoboken, N.J. (1992). Experimental design for continuous processes. The Australian Journal of Statistics, 34(1) : 77-89

9. Silva, A. J., Domingues, M. R., Hirasawa, J. S., Varesche, M. B., Foresti, E. , Zaiat, M. (2011). Kinetic modeling and microbial assessment by fluorescent in situ hybridization in anaerobic sequencing batch biofilm reactors treating sulfaterich wastewater. Braz. J. Chem. Eng. Vol.28:2.

10. Kumar, B. L., Sai Gopal, D. V. R. (2015). Effective role of indigenous microorganisms for sustainable environment. 3 Biotech., 5(6): 867-876.

11.Siddique, T., Okeke, B.C., Arshad, M., Frankenberger, W.T.Jr. (2002). Temperature and pH effects on biodegradation of hexachlorocyclohexane isomers in water and a soil slurry. J Agric Food Chem., 50(18):5070-6.

12. Grady, C.P. Jr., Glen, T. D, Henry, C. L. (1999). Biological Wastewater Treatment. 2nd ed. New York: Marcel Dekker. 